\title{
Structural and longitudinal analysis of the knowledge base on spin-off research
}

\author{
Manuel Portugal Ferreira ${ }^{1,2} \cdot$ Nuno R. Reis ${ }^{2} \cdot$ \\ Roberta M. Paula ${ }^{1}$ Claudia Frias Pinto ${ }^{3}$
}

Received: 21 November 2016/Published online: 20 April 2017

(C) Akadémiai Kiadó, Budapest, Hungary 2017

\begin{abstract}
Following the dynamism in spin-off research, in this study we conduct a structural and longitudinal bibliometric analysis of a sample of 812 articles on spin-offs published in 234 journals included in the ISI Web of Knowledge over a period of three decades. The analyses do not seek to establish a new conceptualization but rather to reveal the intellectual structure of the field and how it has evolved, and the profile of the knowledge network established in the three perspectives: corporate, academic and entrepreneurial spin-offs. The diversity involved in the three streams of spin-off research signals substantial differences. Theoretically, transaction costs, agency and the resource-based view have remained a foundation of spin-off research, albeit that research has been driven more by the phenomena than by developing the theory. The more traditional focus on corporate spin-offs was followed by emphasis on academic spin-offs and more recently on entrepreneurial spin-offs. This shift has been accompanied by a more business/management theoretical orientation, replacing a more financial and taxation-based perspective underlying corporate spin-offs. This study systematizes the existing stock of knowledge and raises avenues for additional inquiry.
\end{abstract}

Keywords Spin-offs · Bibliometric study · Citation analysis · Co-citation analysis · Knowledge base

Manuel Portugal Ferreira

manuel.portugal.ferreira@gmail.com

Graduate School of Management, Universidade Nove de Julho, São Paulo, Brazil

2 School of Technology and Management, Polytechnic Institute of Leiria, Leiria, Portugal

3 FGV/EAESP - Fundação Getúlio Vargas, Sao Paulo, Brazil 


\section{Introduction}

Recent years have been strongly marked by an economic and financial turmoil in several countries around the world, and have brought greater attention from both scholars and public policy makers to the dynamics of new firm creation. New firms are formed through entrepreneurial spin-offs from incumbent firms, and when researchers spin-off from universities and research centers in order to explore knowledge and innovations. In other instances, new spin-offs are formed when established corporations form a separate business unit. However, although dealing with apparently the same phenomenon-spin-offs- the perspectives vary considerably across the type of spin-off. Given the upsurge in publications on spin-offs, it is a useful endeavor to periodically take stock of what has been done in order to better understand the accumulated knowledge from which new research avenues may be uncovered. On a scholarly perspective, it is useful to capture the intellectual structure of spin-off research, the theoretical foundations and how these vary across types of spin-offs.

The concept of spin-offs has been used to characterize new firms' formation mostly in three settings: entrepreneurial, corporate and academic (e.g., Grimaldi et al. 2011; Klepper and Sleeper 2005; Phan et al. 2009; Wallin 2012), each with different characteristics. In common, the three streams have the formation of a new firm. An entrepreneurial spin-off occurs when an employee leaves his/her current employer to start a new venture (Garvin 1983; Klepper and Sleeper 2005; Muendler et al. 2012). The term entrepreneurial spin-off appeared in the 60s, in the neighborhood of Silicon Valley in California (Saxenian 1994). In the initial studies, sometimes the spin-offs were portrayed as created by former employees, possibly disgruntled employees, and it was suggested that the spin-offs had a competitive relationship with the parent firm (Garvin 1983; Klepper 2001). In other instances, spin-offs were described as partially owned by the parent firm but managed independently (Ito 1995; Klepper and Thompson 2006). An academic spin-off refers to a new firm founded by a researcher-an individual student or faculty-that leaves the university or research unit, to create a new start-up firm (Saxenian 1994; Clarysse et al. 2005; Wright et al. 2006), often to explore and exploit novel scientific knowledge or technologies. The academic spin-offs often maintained some ties to the parent research centers, universities, incubators and labs (Chesbrough 2002; Vohora et al. 2004; Shane 2004; Mustar et al. 2006). Academic spin-offs are thus structural forms to leverage research and innovation outcomes (Wright et al. 2006). A different phenomenon is the corporate spin-off (commonly also called spin-out) that, in essence, emerges when a firm is divided into smaller independent units, and are typically methods to divest from unrelated businesses (Chesbrough 2002; Druilhe and Garnsey 2004) or at least to create an autonomous business unit (Ito and Rose 1994; Agarwal et al. 2004; Phan et al. 2009) that buffers the core business. Thus, we may identify different origins of the new firms according to the characteristics of the parent organization, the entrepreneurs, the objectives of the operation; scholars have investigated these using different theoretical perspectives, which have been at least in part a function of the researchers' discipline. These three types of spin-offs have warranted specific streams of enquiry.

Given that research on spin-offs is not recent, what is the current stock of accumulated knowledge on the field? In fact, as put forth by Wallin (2012), given the different milieus in which the term "spin-off" has been used, is there conceptual clarity of the concept itself? Responding to this overarching question leads to the examination of such aspects as what are the main works (articles and/or books) that have had the greatest impact on the field? 
What are the main theories used? What are the main themes that have been studied? In other words, while we accept the common conceptualization of a spin-off as the formation of a new firm, the conceptual underlying foundations vary markedly. For instance, entrepreneurial spin-off research is fundamentally based on management literature and especially on innovation and entrepreneurship; corporate spin-offs have a far greater focus from finance scholars and issues pertaining to taxation.

Hence, to organize, classify and systematize the relevant knowledge we have conducted a bibliometric study of spin-off research published in scientific outlets over the period 1957-2013, with greater emphasis on the last 30 years. Using standard bibliometric procedures and techniques - particularly citation and co-citation-on a sample of 812 articles identified in the ISI Web of Knowledge, we gain a good understanding of the knowledge created by the community. The empirical analyses comprise a structural and a longitudinal component, making it easier to capture a retrospective image, but also demonstrate how research has evolved. The results permit identifying the works that have had the greatest impact on the field, or that have been more influential, the intellectual structure, and the core concentrations of research and how they intertwine. Notably we found that the main theoretical approaches have been the Transaction Costs Theory, more recently the Resource-Based View and its Knowledge-Based variant, and to a lesser extent the agency theory. In any instance, there is a clear influence of the financial field especially in corporate spin-offs. These theoretical emphases are in line with research in other management domains. However, results also seem to indicate that much of the research has been largely atheoretical, meaning that it has been more clearly delimited by the phenomena than by a prevailing conceptual lens.

A thorough literature review permits identifying large dispersion, or fragmentation, of contexts, focus of research, theoretical foundations and phenomena studied. For instance, Garvin (1983) examined spin-offs in a variety of industries, Brittain and Freeman (1986) specifically focused on the semiconductor industry, Franco and Filson (2000) and Agarwal et al. (2004) on the hard disk drive industry and Klepper (2007) on the auto industry in Detroit. Other works have delved into different industries (e.g., Saxenian 1994; Stuart and Sorenson 2003; Klepper and Sleeper 2005; Buenstorf and Klepper 2009). Yet others have taken a cross-industry perspective (Andersson and Klepper 2013). This is evidence that the theme and phenomenon is relevant to many industries. Similarly, some diversity of theoretical views may be observed in spin-off research and this diversity may be at the root of the possible confusions that exist but that are, at least in part, due to the different natures of the spin-offs. For the future development of research on the field, it is thus useful to carry out an extensive review of the extant stock of knowledge on which novel studies may build.

This study contributes in providing a systematization of the stock of knowledge beyond the analysis provided by Wallin (2012) that focused more specifically on describing the most productive scholars, journals of choice, cited authors and journals, and other citationbased metrics. Moreover, this study also contributes more than the existing literature reviews that describe each type of spin-off without making a more comprehensive account of the phenomenon itself. That is, the existing reviews focus, for instance, solely on academic spin-offs (Rothaermel et al. 2007; Mustar et al. 2006; Grimaldi et al. 2011; Perkmann et al. 2013), others on entrepreneurial spin-offs (Klepper 2009; Teixeira 2011), many on corporate spin-offs (Ito and Rose 1994; Rose and Ito 2005; Phan et al. 2009). By jointly analyzing the three types of spin-offs, and not being restricted to a specific type, we also provide a more complete perspective that allows the examination of the common knowledge base that drives the research field but also investigates how they differ. 
We also contribute to the extant knowledge by offering an objective portrayal of the spin-off related research published over more than five decades. Using bibliometric analyses we can examine the stock of knowledge on a given field and trace its evolution over time. Periodically, scholars carry out such endeavors by observing intellectual interconnections, themes, topics and evolutions. In this study we focused specifically on the extant research on spin-offs to uncover the knowledge base of its intellectual structure. Bibliometric studies are an interesting and objective method to conduct large sample literature reviews, despite the drawback of not delving in-depth into the content of the articles. Nonetheless, it is still possible to gain an unbiased panorama of the extant research. Understanding the core works, the theoretical foundations, and the perspectives used may prove crucial in designing future research agendas. This study is thus useful as a starting point for doctoral students and newcomers to the field who may gain a quick grasp of the extant literature, understanding its knowledge foundations, how theories intertwine and the approaches that have been pursued by scholars. It is also relevant for more experienced scholars who may find a broad systematization of the relevant literature.

\section{Brief review on spin-offs: distinguishing types of spin-offs}

The concept of spin-offs has been employed to mean the formation of something new from something that already exists. In the management literature, spin-offs refer to the formation of a new firm from an existing organization, an enterprise or a university or research center. A spin-off occurs when an entrepreneurial employee leaves the employer firm to start his/ her new venture (Klepper and Sleeper 2005), when a corporation decides to split and separate a business unit (Dahlstrand 1997; Phan et al. 2009), or when a professor, researcher, or student exits the university, an incubator or a research center to exploit and explore novel knowledge-based ideas commercially (Klepper 2001; Rothaermel et al. 2007; Grimaldi et al. 2011). There is a largely consensual conceptualization of spin-offs, even if each stream of research delves into spin-offs rather differently. That is, to a large extent the literature has been fragmented according to whether the spin-offs originate from established firms (Dahlstrand 1997; Chesbrough 2002; Klepper 2007; Mayer 2013) or from academia (Lockett et al. 2005; Wright et al. 2006).

Indeed, research on spin-off firms has taken many avenues. Some scholars have studied their impact on regional development (Dahlstrand 1997) and the formation of industry clusters (Porter 1998; Bell et al. 2009; Cruz and Teixeira 2010). Other scholars have delved into the survival and growth of spin-offs (Utterback 1974; Saxenian 1994; Klepper 2001; Pe'er and Keil 2013), into high technology entrepreneurship (Roberts 1991; Myint et al. 2005; Libaers and Meyer 2011), or into creating a taxonomy of research-based spin-offs (Mustar et al. 2006). Other streams have focused on spin-offs as divestments from established corporations (Woo et al. 1992; Ito and Rose 1994; Ito 1995; Rose and Ito 2005) or as opportunities pursued by employees that have acquired knowledge and seek to explore a commercial opportunity they have identified (Klepper 2001).

It is perhaps interesting that research on spin-offs has increased from the early 1990s onwards. For the most part, the two main streams consist of one dealing with corporate spin-offs, and the other dealing with academic spin-offs. A less prominent, albeit growing, stream of research has been on entrepreneurial spinoffs. These three types-corporate spinoffs, academic spin-offs and entrepreneurial spin-offs- have remarkably different traits. Corporate spin-offs are formed when an established firm spins-out a division, usually in a 
business unrelated to its core (Ito and Rose 1994; Ito 1995; Rose and Ito 2005). The way the new business is controlled, the degree of autonomy and its mandate have also been investigated, but much of the research on corporate spin-offs has delved into shareholder value creation, which is assessed using the stock prices after announcement of the spin-off (Hite and Owers 1983; Schipper and Smith 1983; Cusatis et al. 1993). Ito (1995) and Ito and Rose (1994) looked at spin-offs as divestments of mature businesses. Garnsey (1998) and Klepper (2001) observed the conditions at the birth of new spin-offs and the ties to the mother firm-notably how established firms may shield the new spin-offs.

Academic spin-offs are directly tied to universities, research centers, research parks, and incubators that act as wombs in which new spin-off firms are gestated, supporting and providing physical and also reputational resources and legitimacy to the spin-offs. In the academic environment, knowledge creation, novel technologies and the transfer and exploitation of the knowledge by the spin-offs have all gained much importance in the extant studies. Several studies have inquired into academic spin-offs and remarkable accounts may be found pertaining to Silicon Valley in California and MIT in Boston (Klepper 2001; Shane and Stuart 2002; Saxenian 1994), and there are also many accounts referring to spin-offs in Europe (Klepper 2009).

\section{Method}

Methodologically, we conducted a bibliometric study involving a set of procedures for selecting the sample and analyzing the data. Bibliometry consists of the measurement of scientific and technological progress, by applying mathematics and statistics to quantitatively analyze scientific activity and production (Pritchard 1969; Broadus 1987; Börner et al. 2003). Bibliometric analyses rely on scrutinizing written source documents, and mainly published scientific articles (McCain 1990), and also bibliographic information from these documents in order to conduct a set of analyses.

A number of bibliometric studies have been conducted in management/business studies for many different purposes. For instance, Ramos-Rodríguez and Ruíz-Navarro (2004) identified the intellectual structure of strategic management research. Shafique (2013) examined past trends in innovation research and predicted future research arenas. Ferreira et al. (2014) uncovered the main themes or theories in M\&A research, and Shane (1997) described the communities of scholars and their productivity. Despite the popularity of bibliometric studies across disciplines, we found only one study using bibliometric techniques on the field of spin-offs, by Wallin (2012). Regardless of the specific purpose, bibliometric studies are especially useful in academia to organize and classify the extant stock of knowledge on a field, in a manner that would not be possible by following the traditional literature reviews based on content analysis (Börner et al. 2003), because they consider large volumes of data and are based on unbiased selections of the literature.

\section{Procedures for sample selection}

The sample selection involved identifying the articles published in refereed journals available in the ISI Web of Knowledge. This entailed a set of procedures. The first procedure required delimiting the time frame of the study that we defined as 1957 (initial year of the database) to 2013 (data was collected in mid-2014). Second, we delimited the scope of the study only to business and management journals. We did not specify disciplinary 
journals, nor did we restrict the sampling to high impact outlets, in order to gain the broadest overview. Thus, our sample will arguably comprise greater diversity of theoretical views in management/business studies and contexts in which spin-offs have been studied. The third procedure required defining a set of keywords to conduct the search. We have defined simple variations of the term spin-off, in singular and plural form. The search was conducted on the title, abstract and author-supplied keywords. In this manner we guaranteed that the articles identified were related to spin-offs. Nonetheless, all articles were subject to preliminary screening by two researchers, reading at least the title and abstract. Using these criteria we obtained a sample of 812 article published during the 57 years between 1957 and 2013.

\section{Sample}

The sample of this study comprises 812 articles published in 234 journals (the complete list of journals and papers is available from the authors). Plotting the data on a graph (see Fig. 1), an upward trend in publications on spin-offs is clear, most notably after the early 90s. For instance in 2013 there were 53 articles published, which contrasts to only 4 articles in 1957. During the first three decades-60s, 70s and 80s-there was relatively little research on the field, with the period 1957-1983 accounting for only $4 \%$ of the sample (32 articles). However, it is noteworthy that new journals have been founded and the ISI WoK itself has been incorporating additional journals that may account for part of the growth observed. In this study, given the low number of articles published prior to 1983, our analyses will mostly focus on the period post 1984-a 30 years period (1984-2013). It is also worth noting that the large number of journals from which we retrieved the sample (234), reveals that the topic is pertinent in many disciplines.

\section{Procedures for data analysis}

The analysis of the data also involved several procedures. Albeit there are multiple approaches when conducting bibliometric studies, the most common procedures rely on analyzing citation and co-citation data. The social network analyses were complemented

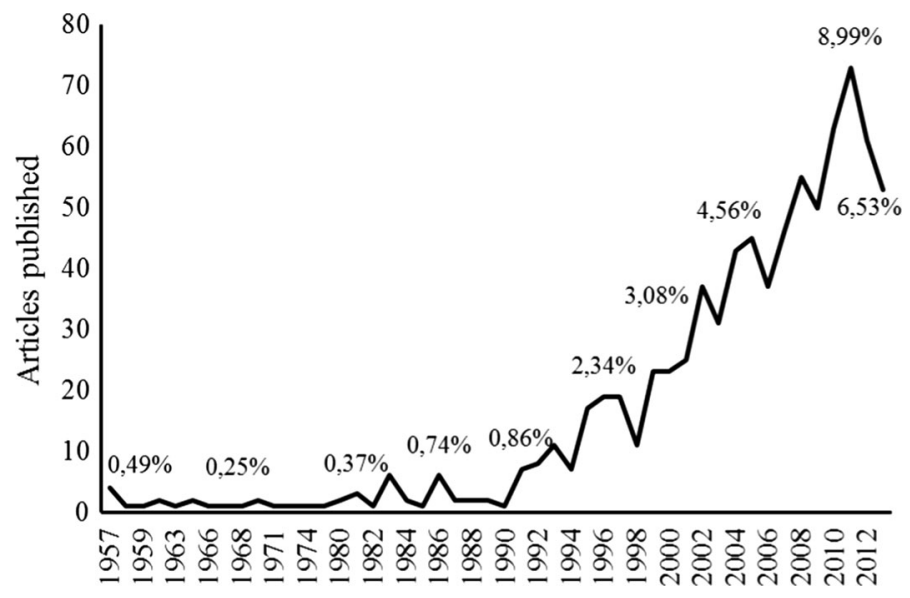

Fig. 1 Evolution of articles published on spin-offs. Source: data collected from the ISI Web of Knowledge 
with a factor analysis (Principal Component Analysis-PCA) to identify possible concentrations - clusters - that may highlight research emphasis. Applying factor analysis to a co-citation matrix (a matrix with the citing papers in columns and the cited papers in rows) it is possible to group the works into major factors based on their commonalities.

\section{Results}

Examining the journals in which the articles were published may also shed some light into the understanding of the extant knowledge. Listing the journals is likely to reveal, at least to some extent, the disciplinary preference for the topic. Moreover, it may help understand the context and meaning of the concept of spin-off. That is, it is reasonable to suggest that knowing which journals have published studies on spin-offs helps in identifying the foundations of the field. Table 1 depicts the 20 journals (jointly accounting for nearly $45 \%$ of the sample, or 363 articles) that have published the most articles on spin-offs.

While some journals are discipline specific, other journals have a broader, or generalist, emphasis. Three main scopes, or groups of journals, emerge: finance, entrepreneurship and regional studies, innovation and strategy. Entrepreneurship journals account for a large portion of the full sample. It is widely acknowledged that journals dedicated to entrepreneurship have a dependence on a diversity of specialties (Teixeira 2011) and

Table 1 Journals with higher number of articles on spin-offs

\begin{tabular}{lcc}
\hline Journals & No. of articles on spin-offs & \% of sample \\
\hline Research Policy & 54 & 6.7 \\
Technovation & 39 & 4.8 \\
Strategic Management Journal & 28 & 3.5 \\
Journal of Taxation & 25 & 3.1 \\
Journal of Technology Transfer & 23 & 2.8 \\
Journal of Financial Economics & 18 & 2.2 \\
Intl Journal of Technology Management & 17 & 2.1 \\
Technology Analysis and Strategic Management & 15 & 1.9 \\
Journal of Corporate Finance & 15 & 1.9 \\
Financial Management & 15 & 1.9 \\
R\&D Management & 13 & 1.6 \\
International Journal of Industrial Organization & 12 & 1.5 \\
Journal of International Business Studies & 12 & 1.5 \\
Small Business Economics & 12 & 1.5 \\
Regional Studies & 11 & 1.4 \\
Industrial and Corporate Change & 11 & 1.4 \\
Journal of Banking and Finance & 11 & 1.4 \\
Journal of Finance & 10 & 1.2 \\
Journal of Management Studies & 10 & 1.2 \\
Journal of Business Venturing & 9 & 1.1 \\
Total & 360 & 44.3 \\
\hline
\end{tabular}


perhaps more especially on business/management. In this regards it is interesting to observe Teixeira's (2011) analyses on the relative disciplinary or multidisciplinary focus of entrepreneurship journals and their ties to innovation, management, economics, finance, and so forth.

The largest number of articles was published in Research Policy, followed by Technovation, the Strategic Management Journal and Journal of Taxation. These are actually very different journals in terms of scope but they reflect the diversity of disciplinary lenses. For instance, the large number of articles on spin-offs in such journals as the Journal of Taxation, Journal of Financial Economics, and Journal of Corporate Finance is due to more financial and tax-related concerns governing corporate spin-offs. Innovation and strategy issues have also been addressed, for instance in the articles published in the Strategic Management Journal. However, the list also includes international business $(J I B S)$ research. The heterogeneity of the list is a reflection of the interest of scholars from different backgrounds on spin-offs, and also of the different interpretations, types and impact of spin-offs.

It is worth noting that often, scholars who are conducting bibliometric studies select the journals based on either impact factors or common understandings of what journals are relevant. By setting the criterion of simply defining the field as business/management, we capture a far larger sample of journals, thus possibly including articles that pursue other arguably less mainstream views. Nonetheless, a bibliometric study could hardly be exhaustive of all journals and, for instance, we are not capturing journals in sociology or economics such as Economic Journal (Buenstorf and Klepper 2009) or Journal of Economic Geography (Wenting 2008) that could be relevant for researchers interested in spinoffs.

\section{Citation analysis}

First, we conducted a citation analysis to identify which works have had the greatest impact on the field. Citation analyses are based on a count of the frequency with which a certain work is referenced by others in their own research papers. Citing existing works is a norm of scientific work, relying on the basic assumption that more cited works tend to hold greater impact, or influence, on a field (Ramos-Rodríguez and Ruíz-Navarro 2004). The core assumption is thus that by observing the most cited works on a given field we are able to understand the foundations of the knowledge base on that field (Tahai and Meyer 1999). Citation analysis is conducted on the references of the papers in our sample - that is, it refers to what the papers in the sample have cited.

Citation analyses posit that the works that have a higher citation count are those that have greater impact (Ramos-Rodríguez and Ruíz-Navarro 2004; Ferreira et al. 2014). Moreover, works that are highly cited across the periods have a more pervasive impact. In addition to a cross-sectional observation of the most cited works, we also trace shifts in citations over time, in a longitudinal analysis, to identify possible variations in research emphasis and its theoretical foundations. The longitudinal analysis was conducted in 5-year periods 1987-1993, 1994-1998, 1999-2003, 2004-2008 and 2009-2013. Albeit largely arbitrary, classifying the data in 5-years periods allows for a sufficiently finegrained analysis while providing meaningful results that are not overcrowded by yearly data. Moreover, the bibliometric techniques used require reasonably large samples and year by year data do not provide a sufficient sample size. The drawback of using citations is that citations may be made for different purposes. For instance, a citation may be made 
for ceremonial reasons, to criticize, to pay homage, to identify or support the use of a methodology, the use of a variable or a data source, among other motives.

Examining citation data, we gain a grasp on the structure of spin-off research and possible changes over time. This analysis provides an initial glance at the content, or foundations, of the field. That is, we gain a better understanding of what research has been about. Table 2 demonstrates those works that were more influential in the entire period. At the top, the papers by Hite and Owers (1983), Schipper and Smith (1983), Roberts (1991), Di Gregorio and Shane (2003) and Cusatis et al. (1993) are seen as the most cited by the source articles in the sample. In Table 2 we also provide a brief description of each work and we will thus not further explain the contributions of these papers. Notwithstanding, we point out the diversity of perspectives encapsulated in these top cited papers and note that they actually represent the different streams and specific concerns that have guided much of the research on spin-offs.

The longitudinal citation analysis (Table 3) provides a panoramic overview of the most cited works and notes how citations have varied over time. Hence, not only do we uncover the relative increase/decrease of citations to certain works-a measure of impact—but also gain an understanding of the conceptual shifts in research in the field. Those articles that are highly cited across periods are likely to have a more continued influence on the field and how it has evolved. Articles whose citation counts have decreased demonstrate that research has moved away from those issues. When examining the patterns, it is worth noting that the time periods defined are largely arbitrary but needed to set points, or intervals, for comparison.

For instance, during the periods 1994-1998 and 1999-2003, the most prominent works were Hite and Owers (1983) Schipper and Smith (1983), and Cusatis et al. (1993), which explore corporate spin-offs' environment and shareholders' wealth. However, there was a decline after this period and in the last 10 years these works have lost some importance (assessed by citation frequencies) and the paper by Hite and Owers (1983) left the top 20 most cited in the last period. This signals that research on corporate spin-offs has at least in part moved away from the effects on stock prices of corporate spin-offs' announcements. In fact, in the last period 2009-2013, entrepreneurial and academic spin-offs are represented by the two top cited papers, and corporate spin-offs had a relative decrease in focus.

Then, during 2004-2008, the works by Roberts (1991), Di Gregorio and Shane (2003), Krishnaswami and Subramaniam (1999), Vohora et al. (2004), Clarysse et al. (2005) captured the largest number of citations. These scholars have emphasized the academic environment, focusing on academic spin-offs gestated in the universities, research centers and incubators. This focus led to research on high technology firms, offices of knowledge/ technology transfer, and academic entrepreneurship. In the period 2009-2013, the most cited were Shane and Stuart (2002), Rothaermel et al. (2007), Shane (2004), Klepper and Sleeper (2005), Cohen and Levinthal (1990), Lockett and Wright (2005), Agarwal et al. (2004). Aspects such as spin-offs' genealogy and influence of the social capital in the gestation and growth of spin-offs also emerge.

\section{Co-citation analysis: intellectual structure}

The second procedure consisted of co-citation analyses. Co-citation analyses are based on identifying joint citations to a pair of works (Small 1973) - interpreted as a measure of similarity (McCain 1990) — from which we may infer the intellectual ties, or intellectual proximity that exists between those works (Small 1973; McCain 1990; Tahai and Meyer 1999; Shafique 2013). The assumption is that the more a pair of works is cited together in 
Table 2 Most cited: 1957-2013

\begin{tabular}{lll}
\hline References & $\frac{\text { Frequency }}{n \%}$ Overview/topic \\
\hline
\end{tabular}

Hite and Owers
(1983)
Schipper and Smith
(1983)

71

\section{7}

67

8.3
Roberts (1991)
Di Gregorio and
Shane (2003)
Miles and Rosenfeld

$65 \quad 8.0$

Vohora et al. (2004) 55
Nelson and Winter 55
(1982)

Shane and Stuart

(2002)

Shane (2004)

Klepper and Sleeper (2005)
Cohen and Levinthal (1990)
Clarysse et al. (2005)

Daley et al. (1997)

Lockett and Wright (2005)

Agarwal et al. (2004)

Saxenian (1994)

Barney (1991)

Siegel et al. (2003)

ÓShea et al. (2005)

Role of founders' resources and social capital on the development of the new firms in the initial stages of the life cycle

6.7 Explains the formation of academic spin-offs and their role in commercializing technologies created at university

6.4 The relation between mother firm and entrepreneurial spin-offs. Spinoffs exploit the knowledge of the mother firm, using the concept of heredity

6.4 Knowledge, knowledge diversity inside organizations and firms' factors that influence absorptive capacity

$50 \quad 6.2$ The strategies, resources and competences for creating spin-outs supported by incubators

$49 \quad 6.0$ Corporate spin-offs create value

$48 \quad 5.9 \quad$ Antecedents and consequences of knowledge transfer from universities to private firms by creating new spin-off firms

5.7 Inheritance, know-how and entrepreneurship by employees that exit a firm to start their businesses. Knowledge-based view

$43 \quad 5.3$ Identifies spin-offs in high tech clusters, based on the knowledge developed and acquired in universities

$43 \quad 5.3$ Seminal work on the RBV. Advanced the VRIN conditions that strategic resources must hold

$42 \quad 5.2$ Offices of technology transfer in universities and the protection of intellectual property of the universities

$42 \quad 5.2$ Resources and capabilities of the universities, including institutional capital, financial, commercial and human for successfully generating spin-offs

Rothaermel et al. (2007)

Cusatis et al. (1993)

Roberts and Malone 40 (1996)

Penrose (1959)

40

415.1 Literature review on academic entrepreneurship, including knowledge transfer, new firms creation, and innovation networks

$5.1 \quad$ Value created by corporate spin-offs

4.9 Five models for creating new firms from the knowledge and resources of universities and research labs

4.9 Seminal on the RBV, portrays firms as bundles of heterogeneous resources dedicated to the production of goods and services. Highlights the importance of R\&D and diversification 


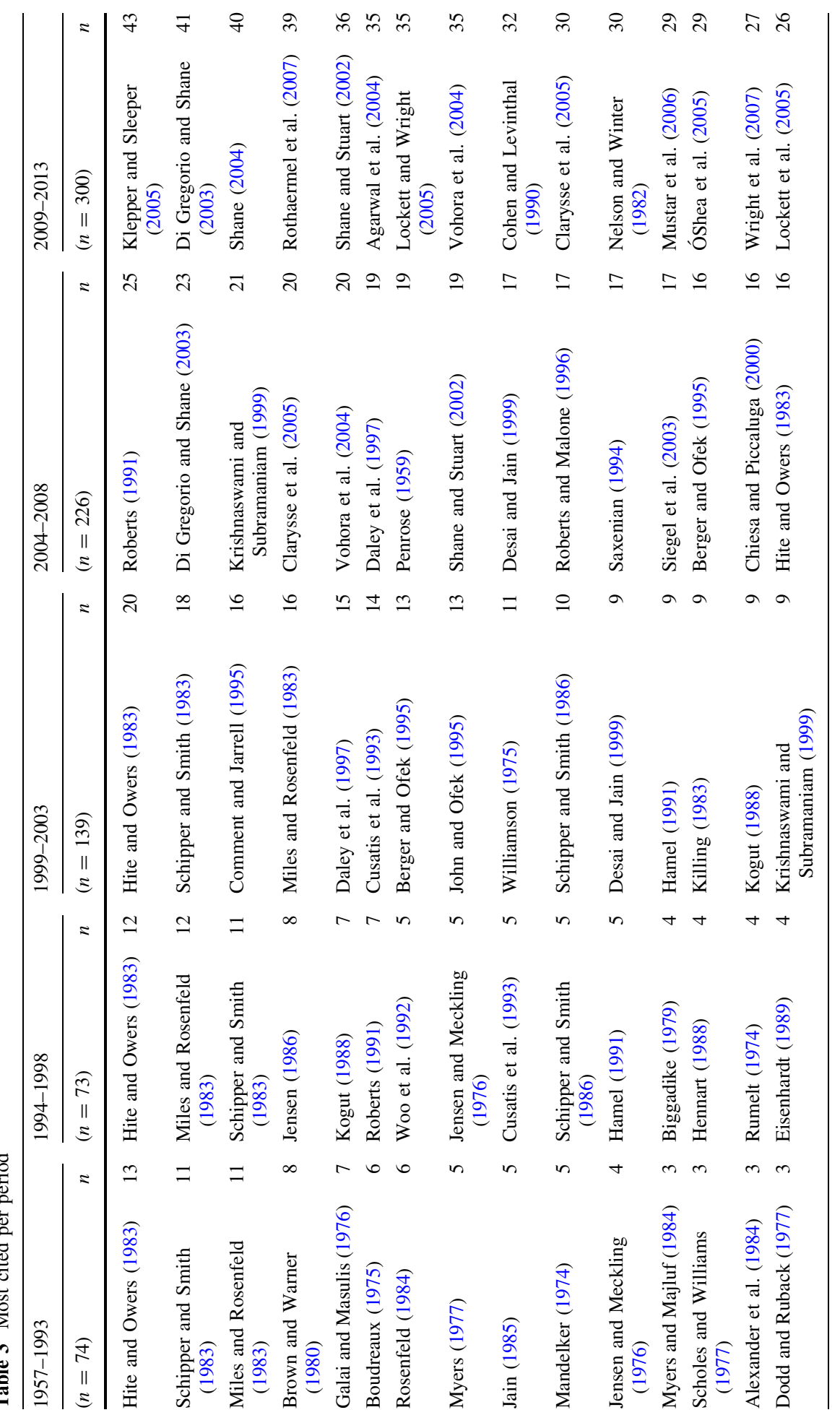




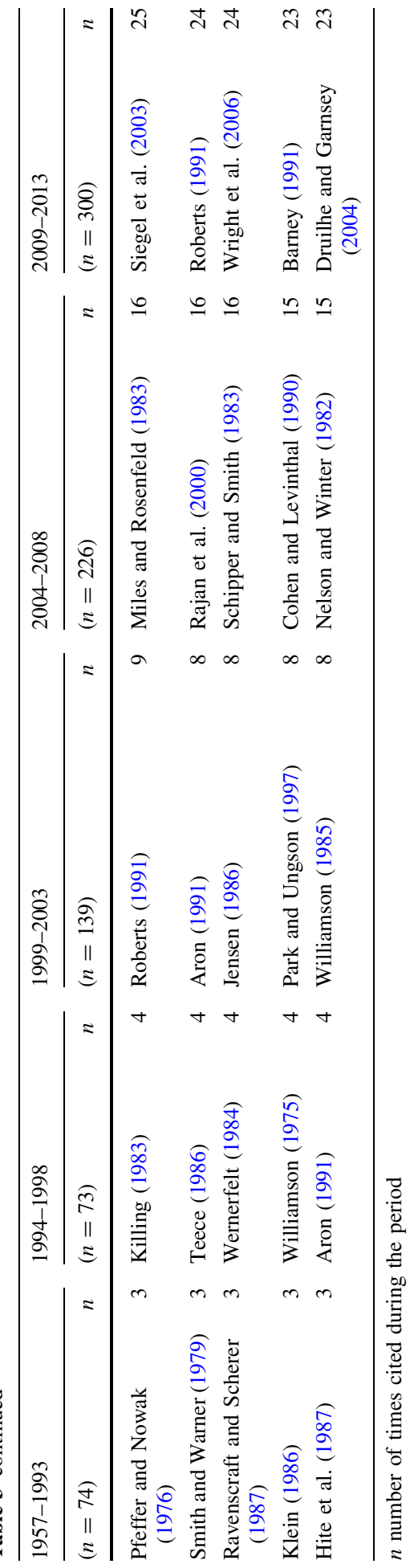


other documents, the more proximate they are (White and McCain 1998) and they are also proximate to the citing document. Hence, co-citation counts measure the strength of the relationship between documents. The co-citation analyses involved a structural examination of the 30 years' period (1984-2013), that was depicted in a network using the social networks software Ucinet. In the network analysis, we identify how the works are intertwined (the ties and the strength of the ties binding works), but we also identify the more central works and those that are at the periphery. Co-citation analyses have already been used to identify the intellectual structure of a field (McCain 1986; Ramos-Rodríguez and Ruíz-Navarro 2004).

To complement our previous longitudinal analyses we also constructed a network and PCA for each period. Interpreting the works on each factor, we can identify what have been the main research streams, theories or perspectives in the field, name and describe each factor. Moreover, we can graphically depict the data-in this case in a network, using Ucinet - to identify the most influential citations in each stream (or factor), how they are related, and their relative positioning (how central or peripheral) in the field. Hence, using co-citation analysis we reveal the topics, authors, research methods, and so forth, that have prevailed in the field, and by examining co-citation data in multiple periods we envision how they may have changed over time (Acedo et al. 2006; Shafique 2013).

It is further worth pointing out that co-citation analyses identify the ties among works in the sample by examining the references used in each of the 812 articles. This analysis identifies intellectual proximity among works, such that the more co-cited a given pair of works, the more proximate they are. Figure 2 is the co-citation network for the period

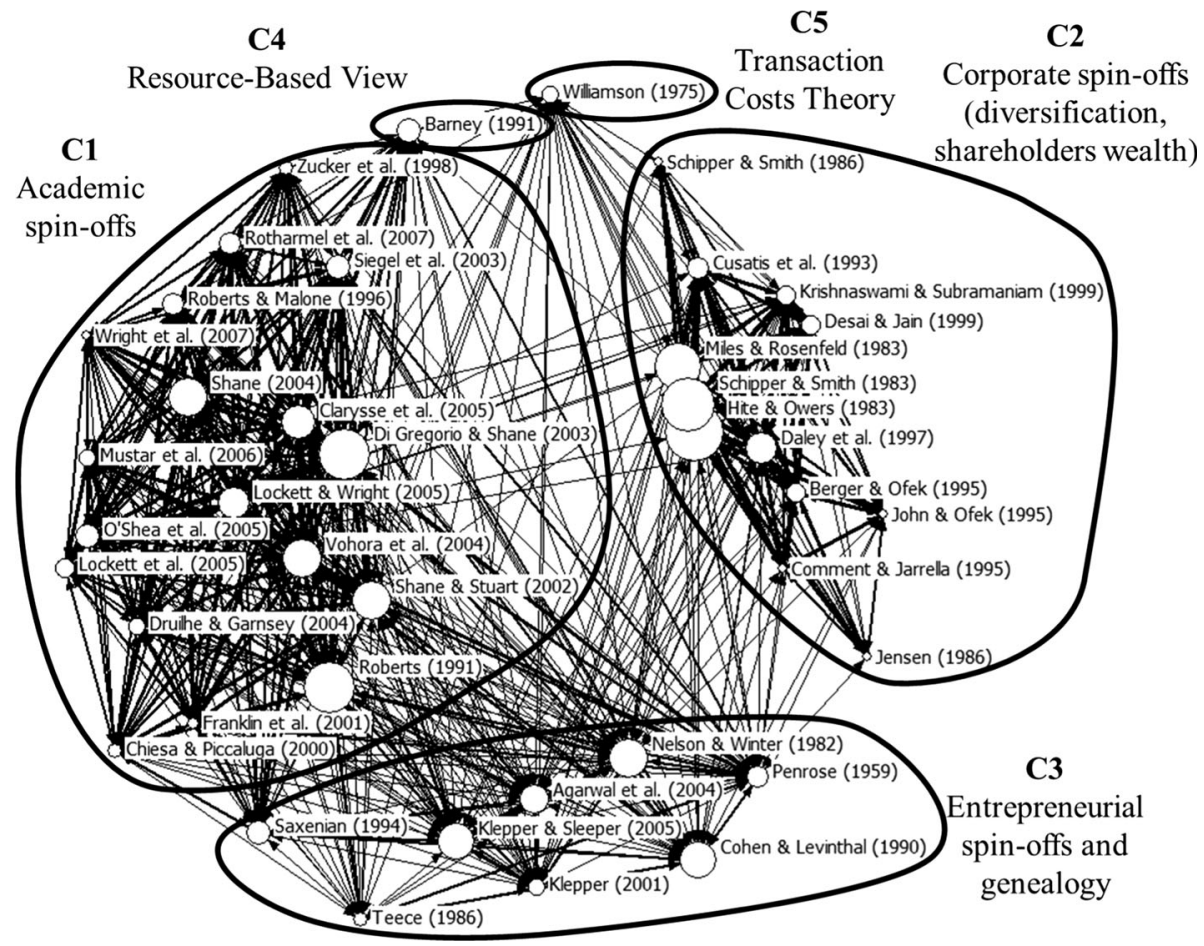

Fig. 2 Co-citation network of the 40 most cited: 1957-2013 
1957-2013. In Fig. 2 the size of the circle is proportional to the number of co-citations of the work (a measure of impact), while the thickness of the line binding a pair of works is proportional to the strength of the tie (number of co-citations of the pair). Hence, thicker lines tie works (articles or books) more often co-cited.

Examining Fig. 2, three concentrations emerge that correspond broadly to academic spin-offs (C1), corporate spin-offs (C2) and entrepreneurial spin-offs (C3). Moreover, two other works appear in isolation but with ties to all three groups: Williamson (1975) on the Transaction Costs Theory and Barney (1991) on the Resource-Based View. These two theories seem to influence all three clusters but are identified in isolation. Moreover, the RBV seems more influential on clusters $\mathrm{C} 3$ on entrepreneurial spin-offs and $\mathrm{C} 1$ on academic spin-offs - as revealed by more ties to the works in these clusters, while the TCT has broad impact on all three clusters.

A brief examination of each cluster is revealing of what they comprise. Cluster Clincludes such works such as Vohora et al. (2004), Di Gregorio and Shane (2003), Shane and Stuart (2002), Roberts (1991), among others, and these show a concentration on the environment for academic spin-offs, incubators, research centers and knowledge transfer. This line of inquiry has followed several paths. For instance, the advantages and disadvantages of spin-offs from universities and academic entrepreneurship (Franklin et al. 2001), the role of universities and offices of technology transfer (Wright et al. 2007), the impact of resources and capabilities of the universities (Lockett and Wright 2005), including institutional capital, financial, commercial and human, for successfully generating spin-offs (ÓShea et al. 2005). Chiesa and Piccaluga (2000) looked at the incentives of universities and research centers to generate spin-offs, and Shane (2004) noted that academic spin-offs may commercialize university developed technologies. In fact, the knowledge environment in universities promotes the commercialization of technologies and the generation of spin-offs, in high tech industries (Zucker et al. 1998). However, other paths have attempted, for example, to understand the role and importance of incubators in gestating successful spin-offs (Roberts 1991; Clarysse et al. 2005).

Cluster C2 is more tightly bound, the central works involved are those of Hite and Owers (1983), Schipper and Smith (1983) and Miles and Rosenfeld (1983). The works in this group converge on studying the effects of spin-offs on corporate wealth. Much of this research has focused on the creation of shareholder wealth, as established diversified firms spin-off business units (Miles and Rosenfeld 1983; Cusatis et al. 1993; Berger and Ofek 1995), looking at such factors as the focus of the firm on its core competences (Jensen 1986; John and Ofek 1995; Daley et al. 1997), negative synergies between mother firm and spin-offs (Schipper and Smith 1986) and separation of under-performing subunits (Desai and Jain 1999).

The third cluster, C3, refers to entrepreneurial spin-offs, and seems to be supported in a learning perspective for competitive advantage. Klepper (2001) examined how spin-offs explore the founders' abilities acquired in their former employment, while Klepper and Sleeper (2005) examine the relation between mother firm and spin-offs, observing how spin-offs are often set to exploit the knowledge of the mother firm. Similar views are shared by Saxenian (1994) who identifies spin-offs in high tech clusters. Agarwal et al. (2004) use a knowledge-based view to explore ideas related to inheritance, know-how and entrepreneurship by employees that exit a firm to start their businesses. This raises issues examined by Teece (1986) pertaining to the appropriation of rents from innovation by innovator firms.

While we are able to use standard statistical techniques to delimit the clusters, or groupings, we are not able to trace the origins of the clusters. That is, why did these 
clusters emerge and what are the articles that have created shift points? Or, stated differently, who initiated the clusters for others to follow? In large part, this is due to a limitation acknowledged in bibliometric studies. We identify papers with higher citation counts but are aware that citation counts are influenced by time (older papers tend to be more cited) but also by other reputation measures (e.g., the reputation of the scholars and schools, and, more importantly, of the journals-higher impact journals are more cited). Nonetheless, inquiry into origins of the clusters seems an interesting endeavor for additional studies.

\section{Themes researched and evolution}

To identify the themes researched on spin-offs, we conducted a factor analysis (PCA) on the co-citation matrixes for 5-years periods. We remind the reader of the arbitrariness of these periods, but some periods have to be set to identify shifts. In conducting the PCA we attributed each work to a single factor based on the highest loading, although it is possible that a work contributes to more than one factor, for example, when it deals with a theory and a specific context (Ferreira et al. 2014). All factors had eigenvalues greater than 1 and all loads were higher than 0.6. PCA extracted five factors for the first period 1994-1998, two factors for 1999-2003 and found a three factor solution for the last two periods: 2004-2008 and 2009-2013. The remaining years, from 1957 to 1993, had too few works to conduct a reliable factor analysis. Examining the works in each factor, it is possible to interpret the factor. The factors, or clusters, identified with the PCA were superimposed on the networks for easier visualization. Finally, we create labels for each grouping based on the content of the papers included.

F4

Performance of divested spin-offs

F1

Corporate restructuring through spin-offs and shareholder wealth
F3

Corporate diversification through spin-offs

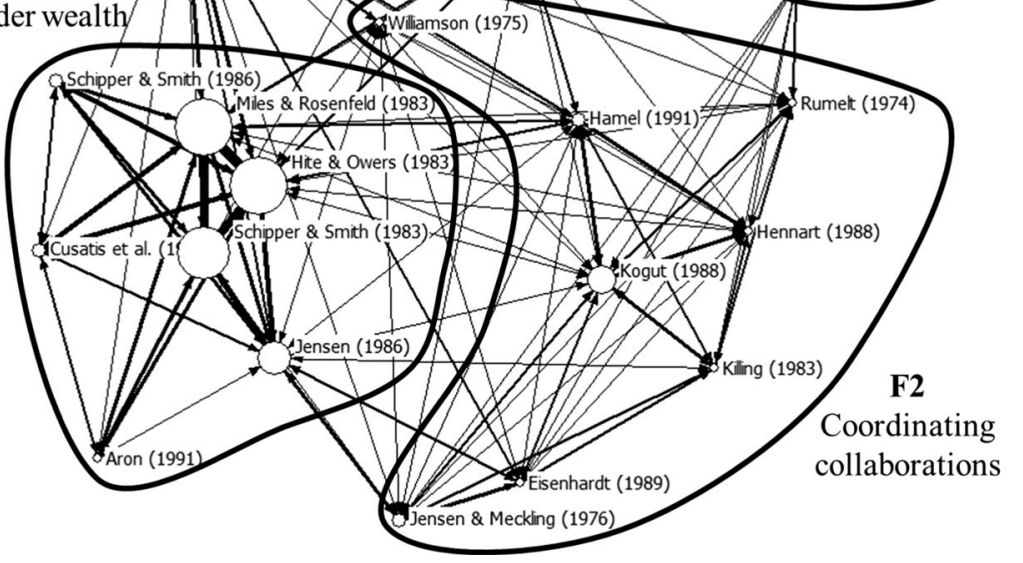

Fig. 3 Co-citation network: 1994-1998 
F2

Transaction costs in

partnering to augment

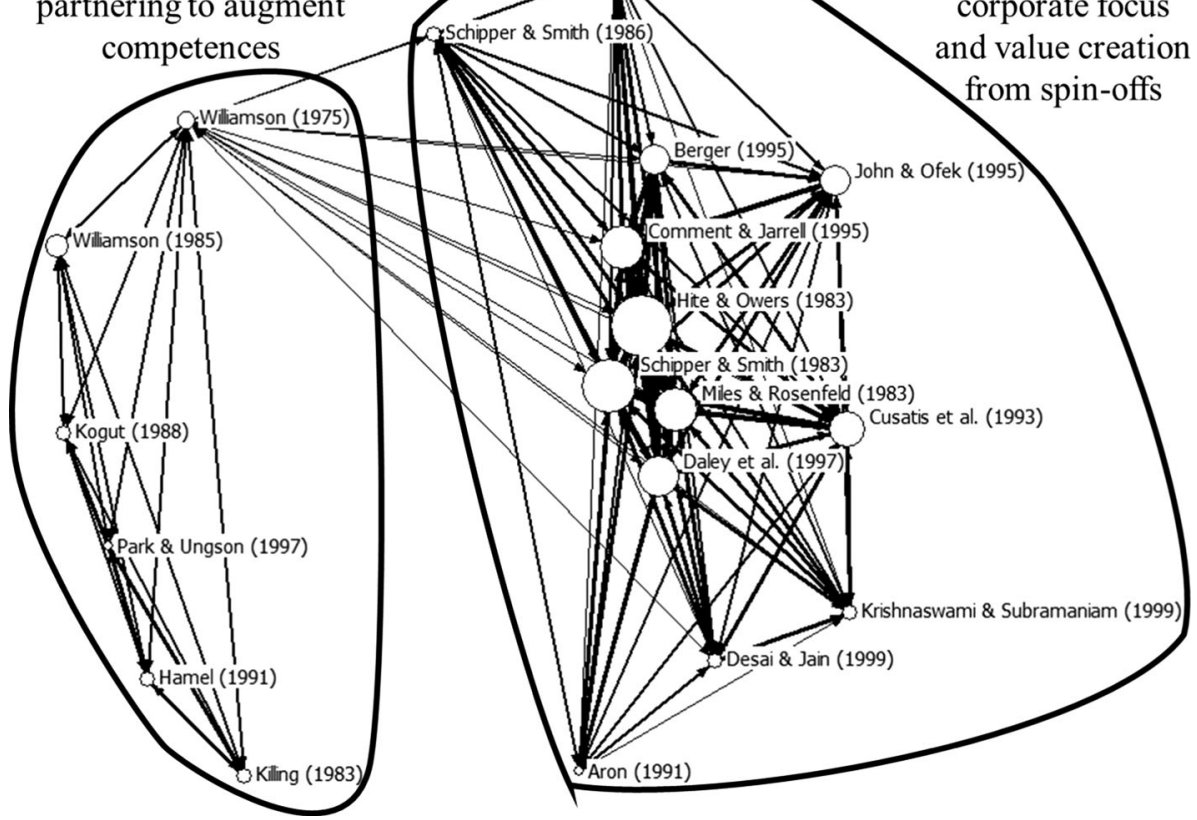

Fig. 4 Co-citation network: 1999-2003

Albeit we identify many shared aspects on the use of the main theoretical perspectives-Transaction Costs Theory, Agency Theory, Resource-Based View and KnowledgeBased View-there are remarkable differences across the four periods. For instance, in the initial periods 1994-1998 and 1999-2003, and arguably even before, research was more concentrated on corporate spin-offs and concerned with shareholders' wealth. In contrast, the creation of spin-offs to explore innovations and knowledge transfer opportunities mainly in the context of academic environments was more pronounced in studies published between 2004-2008 and 2009-2013. In the following section, we briefly examine each period.

The first period, 1994-1998, is characterized by a reasonably dispersed network, with the works by Hite and Owers (1983), Miles and Rosenfeld (1983) and Schipper and Smith (1983) holding greater centrality. The PCA analysis identified five factors, as shown in Fig. 3. These factors, or groupings of more salient works, denote the themes most delved into over the period. In essence, the primary concern over this period seems to have resided in corporate spin-offs and often in examining both the impact of corporate diversification and the stock market reaction to divestitures, or refocusing on the core business, through spin-offs (Hite and Owers 1983; Schipper and Smith 1983).

The period 1999-2003 (Fig. 4) has only two clusters of works that seem to converge on: (F1) diversification, corporate focus and value creation from spin-offs, and (F2) focusing largely on the transaction costs involved in partnering to augment competences. In fact, F1 entails works on divestment, reorganization, focus. For instance, Desai and Jain (1999) looked at firm performance and gains from focus following spin-offs. This group documents a positive stock market reaction to spin-off announcement (Miles and Rosenfeld 1983; Hite 


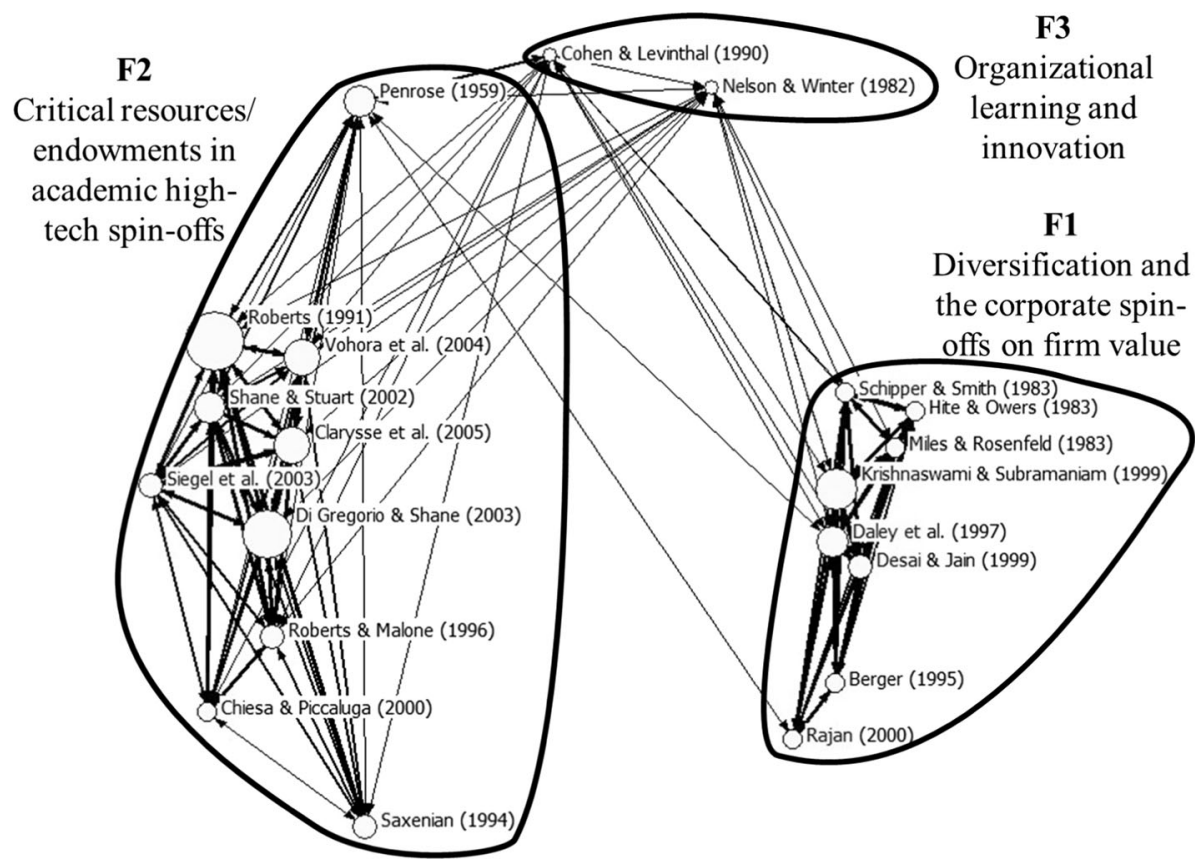

Fig. 5 Co-citation network: 2004-2008

and Owers 1983; Schipper and Smith 1983). The second group largely uses joint ventures, or equity participation in other firms to augment competences and learn, nonetheless revealing the potential hazards. Observation of the network shows that the clusters are tied only by Williamson's (1975) work, also denoting the influence of transaction cost arguments in both groups.

The period 2004-2008 reveals a fragmented network that corresponds to the three concentrations identified in the PCA (see Fig. 5). One (F1) is related to the value of corporate diversification (Berger and Ofek 1995; Rajan et al. 2000) and the effects (shareholder gains) of spin-off announcements that increase corporate focus (Miles and Rosenfeld 1983; Daley et al. 1997; Krishnaswami and Subramaniam 1999).

The second group of works (F2) delves into academic spin-offs and especially deals with the critical resources/endowments in academic high-tech spin-offs gestated by universities, incubators and research centers (Di Gregorio and Shane 2003; Clarysse et al. 2005). This line of research also takes in such studies as Shane and Stuart (2002) on the crucial endowment that is the founders' social capital. Cohen and Levinthal (1990) deliberate on the ability of the firms to recognize the value of new external information, assimilate it and apply it commercially, as a core innovative capability. Moreover, this group has links to understanding the incubation strategies in Europe (Clarysse et al. 2005) and how the academic spin-offs exploit public research. To understand the success of academic spin-offs it is pertinent to understand the organizational factors (Siegel et al. 2003), policies and structures (Roberts and Malone 1996; Di Gregorio and Shane 2003) in place, and the organizational endowments that benefit the university spin-offs (Shane and Stuart 2002; Vohora et al. 2004). 


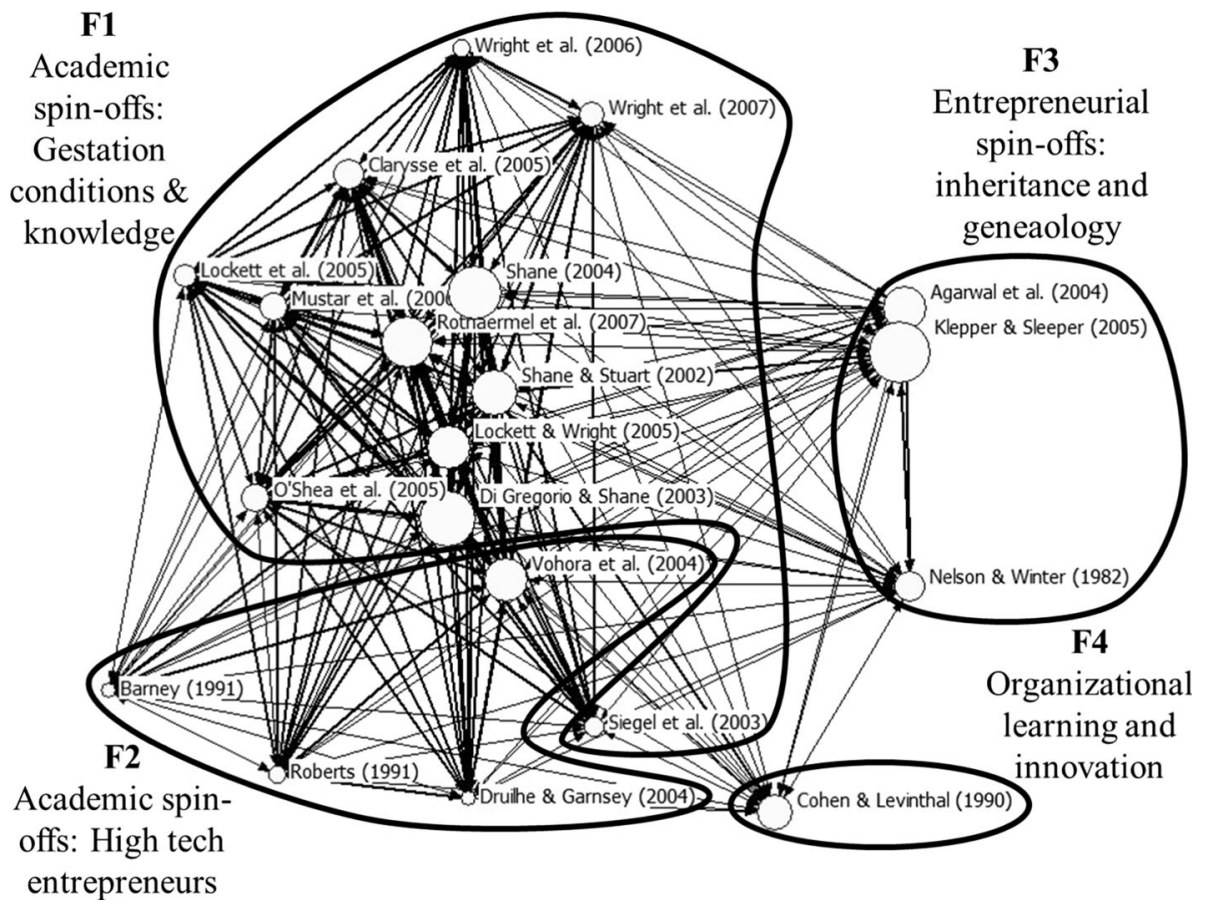

Fig. 6 Co-citation network: 2009-2013

The final group (F3) comprises only two seminal works on organizational learning (Nelson and Winter 1982) and firms' ability to absorb novel knowledge (Cohen and Levinthal 1990). The network further reveals that F2 and F3 have multiple ties, and also F3 and F1 share multiple ties, but F1 and F2 are very scarcely connected, denoting a rather separate perspective between studies on corporate spin-offs and academic spin-offs.

During the last period, 2009-2013, the more central works were Shane and Stuart (2002), Lockett and Wright (2005), Shane (2004), and Di Gregorio and Shane (2003). The PCA analysis resulted in a four factor solution as shown in Fig. 6. The major emphasis in this period was on academic spin-offs and, to a much lesser extent, entrepreneurial spinoffs, but it is the first period where research on corporate spin-offs is less salient. Almost all articles explore the academic environment, at the universities, research centers or academic incubators in generating spin-offs and promoting entrepreneurship. For instance, Clarysse et al. (2005) and Rothaermel et al. (2007) analyzed the influence of the academic environment, specifically at universities and incubators in gestating entrepreneurship. In addition, Di Gregorio and Shane (2003) provided a perspective on why some universities generate more new spin-off firms to exploit the intellectual property developed. Lockett et al. (2005), Vohora et al. (2004) and Wright et al. (2006) examined the role of the new knowledge, and knowledge transfer (see also Siegel et al. 2003; Mustar et al. 2006; ÓShea et al. 2005), at universities was important for new spin-off firms to germinate. Complementary perspectives were put forth by Lockett and Wright (2005) and Shane (2004) delving into the impact of university resources for creating spin-offs and the resource endowments of the entrepreneurs acquired at universities (Shane and Stuart 2002). 
In greater contrast, a few works on entrepreneurial spin-offs, namely by Klepper and Sleeper (2005) that looked at the influence of the mother firm in generating spin-offs, and Agarwal et al. (2004) that, in a knowledge based study approach, inquired into inheritance, know-how and entrepreneurship, thus set the basis for the impact of genealogical aspects that have permeated some research.

\section{Discussion and final remarks}

In this study we sought to organize and classify the extant research on spin-offs. To this end, we have conducted a bibliometric study of the business/management research dealing with spin-offs. On a sample of 812 articles published in journals classified in the ISI Web of Knowledge, over the period from 1957 to 2013, we applied standard citation and cocitation bibliometric techniques. We have identified the works that have had greater impact on the field and their conceptual approaches. A set of longitudinal analyses, using cocitation data treated with both PCA and networks, further provided a rear view perspective on the knowledge base of the field and its evolution.

Research on spin-off firms has generated substantial interest in academia for a number of possible reasons. For public policy makers, there is an interest in economic renewal, growth and employment. For universities, spin-offs are a vehicle for the productive and commercial exploitation of the innovations generated and a possible source of revenue. This is because firms, spin-offs, or corporate spin-offs are seen as a means to streamline operations buffering the core business from the hazards of unrelated businesses. Finally, for entrepreneurs they represent independence and self-fulfillment, by establishing their own businesses using the knowledge acquired or to exploit the opportunities identified. The meanings of spin-offs are thus quite diverse, which was well captured in our study of the different settings where the construct was identified.

In scrutinizing spin-off research it is salient to demonstrate how it aggregates around the three main areas: corporate, academic and entrepreneurial. These three areas have rather profound differences. For instance, performance, or stock market performance, and shareholders' wealth were determining factors on research in corporate spin-offs. Innovation and knowledge, the resource endowments brought by the parent firm to the spin-off firms, technology, $R \& D$, are far more crucial in both academic and entrepreneurial spinoffs. Moreover, the longitudinal analyses revealed a gradual shift first from corporate spinoffs to academic spin-offs and more recently to entrepreneurial spin-offs. This gradual evolution suggests scholars have moved beyond issues pertaining to the structure of the firm, often with a financial approach, following a common trend of other areas of management research (e.g., Ramos-Rodríguez and Ruíz-Navarro 2004) to issues related to the creation and dissemination of knowledge and innovation (in academic spin-offs). This shift was accompanied by a change in the theoretical foundations. For example, looking at spinoffs with innovation/knowledge or entrepreneurial lenses has made more use of the Resource-Based View and of the evolutionary perspective supported in the work of Nelson and Winter (1982).

Nonetheless, albeit we have identified a more recent increasing emphasis on entrepreneurial spin-offs, to some surprise these entrepreneurial spin-offs-described as the situation when an employee exits his/her current employer to start his/her own business, regardless of the underlying motivations-have been much less studied. The growth in this stream may also be evidence that entrepreneurship has been gaining a stronger foothold in 
management schools, with more scholars, journals and degrees offered. Notwithstanding, despite the progress in entrepreneurship studies (see, for instance, Teixeira 2011), entrepreneurship scholars may delve into this type of spin-off to further extend the extant knowledge using alternative theoretical approaches. In fact, it is likely that the phenomena studied when scrutinizing corporate and academic spin-offs are relevant in an entrepreneurial perspective.

An interesting result when observing the entire period (see Fig. 2) is that two core management theories - the Transaction Costs Theory and the Resource-Based View (and its Knowledge-Based view variant) — seem to hold ties to all three streams of thought on spinoffs. That means a focus on both exploring and exploiting the resource base, but it is also influenced by a focus on knowledge. The Resource- and Knowledge-based views reinforce the importance of tangible and intangible resources to attain a competitive advantage. This is especially relevant for new spin-offs whereby the environment in universities and research centers may provide those resources (Roberts 1991; Di Gregorio and Shane 2003; Vohora et al. 2004; Clarysse et al. 2005; ÓShea et al. 2005). However, it is also important for entrepreneurial spin-offs, especially those based on high technology and innovations.

Transaction costs prevailed in the initial periods and were often tied to the impact of spin-off announcements, shareholder wealth and divestments (Williamson 1975; Hite and Owers 1983; Schipper and Smith 1983) — that is, to corporate spin-offs and the impact of value creation, usually in respect to market capitalization. To a considerably less extent, spin-off research has also brought in Agency theory. Agency theory portrays the conflicts of interest between owners/shareholders and managers/employees, and discusses the mechanisms to guarantee the alignment of managers' behaviors with shareholders' interests (Miles and Rosenfeld 1983; Jensen 1986).

The longitudinal analyses also reveal changes in the theoretical foundations over the period. To some extent those changes occur because of the relative shift in focus from corporate to entrepreneurial spin-offs, as explained. Thus, while agency theory, concerns over shareholders' wealth, corporate diversification and stock market reactions to divestitures dominated research endeavors in examining corporate spin-offs, a more management perspective focused on innovation, knowledge transfer and the exploitation of opportunities gain salience when studying academic and entrepreneurial spin-offs. Interestingly researchers started using transaction costs theory to further explore even corporate spin-offs and gradually moved to examine the impact on firm performance. This trend was rich in exploring phenomena such as the gains from focusing on the competences, the value creation following spin-offs and the learning that may emerge from shared ownership structures.

It is by the mid 2000s that research on spin-offs more clearly fragments in the three streams-corporate, academic and entrepreneurial - and that the theoretical foundations consolidate in how they are used by each stream. We then observe a wealth of studies much more targeting at innovation, knowledge and learning, but also targeting aspects more often dealt with by entrepreneurship scholars such as the founders' networks, social capital and the new firms' resource endowments. Nonetheless, there is also some convergence between academic and entrepreneurial spin-offs research as the literature on research parks, incubators and more recently on the entrepreneurial ecosystems emerges.

\section{Limitations and further research}

This study has some limitations-first, the limitations pertaining to the method itself. Bibliometric techniques are useful for dealing quantitatively with large datasets but less useful to delve into the content of the source documents. Hence, using bibliometric 
techniques we are unaware of the motivations governing citations and co-citations; and scientific papers may be cited with different purposes, such as to complement an argument, use a theory, contrast findings, or criticize. Thus, our analysis does not exclude, but rather complements, the need for a through literature review. This limitation may be easily overcome using content analysis software.

Another limitation pertains to the set of keywords used to search the articles. Our criteria were rather strict and by searching the title, abstract and author-supplied keywords we sought to capture those articles that actually deal with spin-offs and not those that only somehow address the phenomenon. Hence, we believe we capture the most relevant works but our results are not exhaustive. Finally, it is worth noting that an alternative method to uncover the main research themes entails a content analysis; which could lead to rather biased examinations, and is rather unviable when dealing with such a large sample. Another alternative procedure was presented by Ferreira et al. (2014) that coded the author-supplied keywords into major themes, but each work may fall into multiple themes and the themes combine both theory and phenomena, rendering the analysis complex.

We have used articles published in journals classified in ISI Web of Knowledge. However, other journals outside this database - that do not have an impact factor-or that are not classified in business/management may also publish studies on spin-offs. Nonetheless, even considering that our sample is not exhaustive, the 234 journals included in our sample already comprise the most reputable journals and are thus more likely to drive the evolution of the field. Moreover, we have used only published articles, but bibliometric studies may use other source documents such as books, conference papers, reports and so forth. While it is possible that additional details could be captured, it is not clear whether those documents comprise different approaches to the study of spin-offs.

It is likely that entrepreneurial spin-offs are the least studied in contrast to corporate and university spin-offs. This stream of research has been led by scholars such as Klepper, Agarwal, Freeman and others, but the number of studies on entrepreneurial spin-offs is substantially smaller than that on either corporate or academic spin-offs, as demonstrated by our analysis. However, for public policy and the promotion of economic activity, a sound understanding of entrepreneurial spin-offs is desirable. To complement existing studies it may be interesting to inquire how the entrepreneurs' intangible resources (e.g., social capital) may influence the success of the new spin-offs. Another line of research may be to examine the relation between the spin-offs and the parent firms - that is, whether entrepreneurial spin-offs compete or complement the parent firm, the benefits from the resource pool of the mother, the ties binding spin-offs and parent firms, and so forth. Indeed, this line of inquiry is likely to be valuable for both entrepreneurship and regional development researchers.

Research on spin-offs still has many avenues to pursue, perhaps more notably in entrepreneurial dynamics and incorporating a stronger theoretical foundation that goes beyond casuistic observations of the phenomenon. In particular, empirical research may be especially fruitful to bring some closure to inconsistent findings on the performance effects, but also may be valuable in such facets as clearly scrutinizing the resource endowments that spin-offs absorb from their parent firms or originating organization. The role of the institutions warrants attention besides the stock market effect in corporate spinoffs in promoting and sustaining the spin-offs, and may probably require further study into the legal and cultural environment. 


\section{References}

Acedo, F., Barroso, C., \& Galan, J. (2006). The resource-based theory: Dissemination and main trends. Strategic Management Journal, 27(7), 621-636.

Agarwal, R., Echambadi, R., Franco, A., \& Sarkar, M. (2004). Knowledge transfer through inheritance: Spin-out generation, development and survival. Academy of Management Journal, 47(4), 501-522.

Alexander, G., Benson, B., \& Kampmeyer, J. (1984). Investigating the valuation effects of announcements of voluntary corporate selloffs. The Journal of Finance, 39(2), 503-517.

Andersson, M., \& Klepper, S. (2013). Characteristics and performance of new firms and spinoffs in Sweden. Industrial and Corporate Change, 22(1), 245-280.

Aron, D. (1991). Using the capital market as a monitor: Corporate spinoffs in an agency framework. The RAND Journal of Economics, 22(4), 505-518.

Barney, J. (1991). Firm resources and sustained competitive advantage. Journal of Management, 17(1), 99-120.

Bell, S., Tracey, P., \& Heide, J. (2009). The organizational of regional clusters. Academy of Management Review, 34(4), 623-642.

Berger, P., \& Ofek, E. (1995). Diversificatiońs effect on firm value. Journal of Financial Economics, 37(1), 39-65.

Biggadike, R. (1979). The risky business of diversification. A bold approach can make all the difference in new ventures. Harvard Business Review, 56(1), 103-111.

Börner, K., Chen, C., \& Boyack, K. (2003). Visualizing knowledge domains. Annual Review of Information Science and Technology, 37(1), 179-255.

Boudreaux, K. (1975). Divestiture and share price. Journal of Financial and Quantitative Analysis, 10(4), $619-626$.

Brittain, J., \& Freeman, J. (1986). Entrepreneurship in the semiconductor industry. Unpublished manuscript. Berkeley, CA: University of California.

Broadus, R. (1987). Towards a definition of "bibliometrics". Scientometrics, 12(5), 373-379.

Brown, S., \& Warner, J. (1980). Measuring security price performance. Journal of Financial Economics, $8(3), 205-258$.

Buenstorf, G., \& Klepper, S. (2009). Heritage and agglomeration: The Akron tire cluster revisited. The Economic Journal, 119(537), 705-733.

Chesbrough, H. (2002). Graceful exits and missed opportunities: Xerox's management of its technology spin-off organizations. Business History Review, 76(4), 803-837.

Chiesa, V., \& Piccaluga, A. (2000). Exploitation and diffusion of public research: The case of academic spin-off companies in Italy. R\&D Management, 30(4), 329-340.

Clarysse, B., Wright, M., Lockett, A., Van De Velde, E., \& Vohora, A. (2005). Spinning out new ventures: A typology of incubation strategies from European research institutions. Journal of Business Venturing, 20(2), 183-216.

Cohen, W., \& Levinthal, D. (1990). Absorptive capacity: A new perspective on learning and innovation. Administrative Science Quarterly, 35(1), 128-152.

Comment, R., \& Jarrell, G. (1995). Corporate focus and stock returns. Journal of Financial Economics, $37(1), 67-87$.

Cruz, S., \& Teixeira, A. (2010). The evolution of the cluster literature: Shedding light on the regional studies-regional science debate. Regional Studies, 44(9), 1263-1288.

Cusatis, P., Miles, J., \& Woolridge, J. (1993). Restructuring through spinoffs: The stock market evidence. Journal of Financial Economics, 33(3), 293-311.

Dahlstrand, A. (1997). Growth and inventiveness in technology-based spin off firms. Research Policy, 26(3), 331-344.

Daley, L., Mehrotra, V., \& Sivakumar, R. (1997). Corporate focus and value creation evidence from spinoffs. Journal of Financial Economics, 45(2), 257-281.

Desai, H., \& Jain, P. (1999). Firm performance and focus: Long-run stock market performance following spinoffs. Journal of Financial Economics, 54(1), 75-101.

Di Gregorio, D., \& Shane, S. (2003). Why do some universities generate more start-ups than others? Research Policy, 32(2), 209-227.

Dodd, P., \& Ruback, R. (1977). Tender offers and stockholder returns: An empirical analysis. Journal of Financial Economics, 5(3), 351-373.

Druilhe, C., \& Garnsey, E. (2004). Do academic spin-outs differ and does it matter? Journal of Technology Transfer, 29(3/4), 269-285.

Eisenhardt, K. (1989). Making fast strategic decisions in high-velocity environments. Academy of Management Journal, 32(3), 543-576. 
Ferreira, M., Santos, J., Reis, N., \& Almeida, M. (2014). Mergers \& acquisitions research: A bibliometric study of top strategy and international business journals, 1980-2010. Journal of Business Research, 67(12), 2250-2258.

Franco, A., \& Filson, D. (2000). Knowledge diffusion through employee mobility. Staff Report 272. Federal Reserve Bank of Minneapolis Research Department, pp. 1-59.

Franklin, S., Wright, M., \& Lockett, A. (2001). Academic and surrogate entrepreneurs in university spin-out companies. Journal of Technology Transfer, 26(1-2), 127-141.

Galai, D., \& Masulis, R. (1976). The option pricing model and the risk factor of stock. Journal of Financial Economics, 3(1-2), 53-81.

Garnsey, E. (1998). The genesis of the high technology milieu: A study in complexity. International Journal of Urban and Regional Research, 22(3), 361-377.

Garvin, D. (1983). Spin-offs and the new firm formation process. California Management Review, 25(2), $3-20$.

Grimaldi, R., Kenney, M., Siegel, D., \& Wright, M. (2011). 30 years after Bayh-Dole: Reassessing academic entrepreneurship. Research Policy, 40(8), 1045-1057.

Hamel, G. (1991). Joint ventures: Competition for competence and inter-partner learning within international strategic alliances. Strategic Management Journal, 12(S1), 83-103.

Hennart, J. (1988). A transaction costs theory of equity joint ventures. Strategic Management Journal, 9(4), 361-374.

Hite, G., \& Owers, J. (1983). Security price reactions around corporate spin-off announcements. Journal of Financial Economics, 12(4), 409-436.

Hite, G., Owers, J., \& Rogers, R. (1987). The market for interfirm asset sales: Partial sell-offs and total liquidations. Journal of Financial Economics, 18(2), 229-252.

Ito, K. (1995). Japanese spinoffs: Unexplored survival strategies. Strategic Management Journal, 16(6), 431-446.

Ito, K., \& Rose, E. (1994). The genealogical structure of Japanese firms parent-subsidiary relationships. Strategic Management Journal, 15(S2), 35-51.

Jain, P. (1985). The effect of voluntary sell-off announcements on shareholder wealth. The Journal of Finance, 40(1), 209-224.

Jensen, M. (1986). Agency costs of free cash flow, corporate finance, and takeovers. The American Economic Review, 76(2), 323-329.

Jensen, M., \& Meckling, W. (1976). Theory of the firm: Managerial behavior, agency costs and ownership structure. Journal of Financial Economics, 3(4), 305-360.

John, K., \& Ofek, E. (1995). Asset sales and increase in focus. Journal of Financial Economics, 37(1), $105-126$.

Killing, J. (1983). Strategies for joint venture success. New York, NY: Praeger.

Klein, A. (1986). The time and substance of divestiture announcements: Individual, simultaneous and cumulative effects. The Journal of Finance, 41(3), 685-696.

Klepper, S. (2001). Employee startups in high-tech industries. Industrial and Corporate Change, 10(3), $639-674$.

Klepper, S. (2007). Disagreements, spinoffs, and the evolution of Detroit as the capital of the US automobile industry. Management Science, 53(4), 616-631.

Klepper, S. (2009). Spinoffs: A review and synthesis. European Management Review, 6(3), 159-171.

Klepper, S., \& Sleeper, S. (2005). Entry by spinoffs. Management Science, 51(8), 1291-1306.

Klepper, S., \& Thompson, P. (2006). Intra-industry spinoffs. Carnegie Mellon University Florida International University, Working paper, pp. 1-37.

Kogut, B. (1988). Joint ventures: Theoretical and empirical perspectives. Strategic Management Journal, 9(4), 319-332.

Krishnaswami, S., \& Subramaniam, V. (1999). Information asymmetry, valuation, and the corporate spin-off decision. Journal of Financial Economics, 53(1), 73-112.

Libaers, D., \& Meyer, M. (2011). Highly innovative small technology firms, industrial clusters and firm internationalization. Research Policy, 40(10), 1426-1437.

Lockett, A., Siegel, D., Wright, M., \& Ensley, M. (2005). The creation of spin-off firms at public research institutions: Managerial and policy implications. Research Policy, 34(7), 981-993.

Lockett, A., \& Wright, M. (2005). Resources, capabilities, risk capital and the creation of university spin-out companies. Research Policy, 34(7), 1043-1057.

Mandelker, G. (1974). Risk and return: The case of merging firms. Journal of Financial Economics, 1(4), 303-335.

Mayer, H. (2013). Entrepreneurship in a hub-and-spoke industrial district: Firm survey evidence from Seattle's technology industry. Regional Studies, 47(10), 1715-1733. 
McCain, K. (1986). Co-cited author mapping as a valid representation of intellectual structure. Journal of the American Society for Information Science, 37(3), 111-122.

McCain, K. (1990). Mapping authors in intellectual space: A technical overview. Journal of the American Society for Information Science, 41(6), 433-443.

Miles, J., \& Rosenfeld, J. (1983). An empirical analysis of the effects of spin-off announcements on shareholder wealth. Journal of Finance, 38(5), 1597-1606.

Muendler, M., Rauch, J., \& Tocoian, O. (2012). Employee spin-offs and other entrants: Stylized facts from Brazil. International Journal of Industrial Organization, 30(5), 447-458.

Mustar, P., Renault, M., Colombo, M., Piva, E., Fontes, M., Lockett, A., et al. (2006). Conceptualizing the heterogeneity of research-based spin-offs: A multi-dimensional taxonomy. Research Policy, 35(2), 289-308.

Myers, S. (1977). Determinants of corporate borrowing. Journal of Financial Economics, 5(2), 147-175.

Myers, S., \& Majluf, N. (1984). Corporate financing and investment decisions when firms have information that investors do not have. Journal of Financial Economics, 13(2), 187-221.

Myint, Y., Vyakarnam, S., \& New, M. (2005). The effect of social capital in new venture creation: The Cambridge high-technology cluster. Strategic Change, 14(3), 165-177.

Nelson, R., \& Winter, S. (1982). An evolutionary theory of economic change. Cambridge, MA: The Belknap Press of Harvard University.

ÓShea, R., Allen, T., Chevalier, A., \& Roche, F. (2005). Entrepreneurial orientation, technology transfer and spinoff performance of U.S. universities. Research Policy, 34(7), 994-1009.

Park, S., \& Ungson, G. (1997). The effect of national culture, organizational complementarity, and economic motivation on joint venture dissolution. Academic of Management Journal, 40(2), 279-307.

Pe'er, A., \& Keil, T. (2013). Are all startups affected similarly by clusters? Agglomeration, competition, firm heterogeneity, and survival. Journal of Business Venturing, 28(3), 354-372.

Penrose, E. (1959). The theory of the growth of the firm. New York, NY: Oxford University Press.

Perkmann, M., Tartari, V., McKelvey, M., Autio, E., Broström, A., D’Este, P., et al. (2013). Academic engagement and commercialisation: A review of the literature on university-industry relations. $R e$ search Policy, 42(2), 423-442.

Pfeffer, J., \& Nowak, P. (1976). Joint ventures and interorganizational interdependence. Administrative Science Quarterly, 21(3), 398-418.

Phan, P., Wright, M., Ucbasaran, D., \& Tan, W.-L. (2009). Corporate entrepreneurship: Current research and future directions. Journal of Business Venturing, 24, 197-205.

Porter, M. (1998). Cluster and the new economics of competition. Harvard Business Review, 76(6), 77-90.

Pritchard, A. (1969). Statistical bibliography or bibliometrics? Journal of Documentation, 25(4), 348-349.

Rajan, R., Servaes, H., \& Zingales, L. (2000). The cost of diversity: The diversification discount and inefficient investment. The Journal of Finance, 55(1), 35-80.

Ramos-Rodríguez, A., \& Ruíz-Navarro, J. (2004). Changes in the intellectual structure of strategic management research: A bibliometric study of the Strategic Management Journal, 1980-2000. Strategic Management Journal, 25(10), 981-1004.

Ravenscraft, D., \& Scherer, F. (1987). Mergers, sell-offs and economic efficiency. Washington, DC: The Brookings Institution.

Roberts, E. (1991). High tech entrepreneurs: Lessons from MIT and beyond. New York, NY: Oxford University Press.

Roberts, E., \& Malone, D. (1996). Policies and structures for spinning off new companies from research and development organizations. $R \& D$ Management, 26(1), 17-48.

Rose, E., \& Ito, K. (2005). Widening the family circle: Spin-offs in the Japanese service sector. Long Range Planning, 38(1), 9-26.

Rosenfeld, J. (1984). Additional evidence on the relation between divestiture announcements and shareholder wealth. The Journal of Finance, 39(5), 1437-1448.

Rothaermel, F., Agung, S., \& Jiang, L. (2007). University entrepreneurship: A taxonomy of the literature. Industrial and Corporate Change, 16(4), 691-791.

Rumelt, R. (1974). Strategy, structure, and economic performance. Cambridge, MA: Harvard University Press.

Saxenian, A. (1994). Regional advantage: Culture and competition in Silicon Valley and Route 128. Cambridge, MA: Harvard University Press.

Schipper, K., \& Smith, A. (1983). Effects of recontracting on shareholder wealth: The case of voluntary spin-offs. Journal of Financial Economics, 12(4), 437-467.

Schipper, K., \& Smith, A. (1986). A comparison of equity carve-outs and seasoned equity offerings: Share price effects and corporate restructuring. Journal of Financial Economics, 15(1-2), 153-186. 
Scholes, M., \& Williams, J. (1977). Estimating betas from nonsynchronous data. Journal of Financial Economics, 5(3), 309-327.

Shafique, M. (2013). Thinking inside the box? Intellectual Structure of the knowledge base of Innovation research (1988-2008). Strategic Management Journal, 34(1), 62-93.

Shane, S. (1997). Who is publishing the entrepreneurship research? Journal of Management, 23(1), 83-95.

Shane, S. (2004). Academic entrepreneurship. University spinoffs and wealth creation. Northampton, MA: Edward Elgar Publishing.

Shane, S., \& Stuart, T. (2002). Organizational endowments and the performance of university start-ups. Management Science, 48(1), 154-170.

Siegel, D., Waldman, D., \& Link, A. (2003). Assessing the impact of organizational practices on the relative productivity of university technology transfer offices: An exploratory study. Research Policy, 32(1), $27-48$.

Small, H. (1973). Co-citation in the scientific literature: A new measure of the relationship between two documents. Journal of the American Society for Information Science, 24(4), 265-269.

Smith, C., \& Warner, J. (1979). On financial contracting: An analysis of bond covenants. Journal of Financial Economics, 7(2), 117-161.

Stuart, T., \& Sorenson, O. (2003). Liquidity events and the geographic distribution of entrepreneurial activity. Administrative Science Quarterly, 48(2), 175-201.

Tahai, A., \& Meyer, M. (1999). A revealed preference study of management journals' direct influences. Strategic Management Journal, 20(3), 279-296.

Teece, D. (1986). Profiting from technological innovation: Implications for integration, collaboration, licensing and public policy. Research Policy, 15(6), 285-305.

Teixeira, A. (2011). Mapping the (in) visible college (s) in the field of entrepreneurship. Scientometrics, $89(1), 1-36$.

Utterback, J. (1974). Innovation in industry and the diffusion of technology. Science, 183(4125), 620-626.

Vohora, A., Wright, M., \& Lockett, A. (2004). Critical junctures in the growth in university high-tech spinout companies. Research Policy, 33(1), 147-175.

Wallin, M. (2012). The bibliometric structure of spin-off literature. Innovation: Management, Policy \& Practice, 14(2), 162-177.

Wenting, R. (2008). Spinoff dynamics and the spatial formation of the fashion design industry, 1858-2005. Journal of Economic Geography, 8(5), 593-614.

Wernerfelt, B. (1984). A resource-based view of the firm. Strategic Management Journal, 5(2), 171-180.

White, H., \& McCain, K. (1998). Visualizing a discipline: An author co-citation analysis of information science, 1972-1995. Journal of the American Society for Information Science, 49(4), 327-355.

Williamson, O. (1975). Markets and hierarchies, analysis and antitrust implications: A study in the economics of internal organization. Philadelphia. PA: The Free Press.

Williamson, O. (1985). The economic institutions of capitalism: Firms, markets, relational contracting. New York, NY: Free Press.

Woo, C., Willard, G., \& Daellenbach, U. (1992). Spin-off performance: A case of overstated expectations? Strategic Management Journal, 13(6), 433-447.

Wright, M., Clarysse, B., Mustar, P., \& Lockett, A. (2007). Academic entrepreneurship in Europe. Northampton, MA: Edward Elgar Publishing.

Wright, M., Lockett, A., Clarysse, B., \& Blinks, M. (2006). University spin-out companies and venture capital. Research Policy, 35(4), 481-501.

Zucker, L., Darby, M., \& Brewer, A. (1998). Intellectual human capital and the birth of U.S. biotechnology enterprises. The American Economic Review, 88(1), 290-306. 